\title{
Empathic Design: A Study of Media Information Concept Design and The Virtual Home
}

\author{
Shu-huei Wang \\ MingDao University, ChangHua, Taiwan
}

\begin{abstract}
This research tried to propose possible ways to resolve the paper over-consumption issues. The nature resources have been over used all the time. How we used the technologies to solve environmental problems has become an essential issue. How we could develop a prosperous vision for the future is even critical to solving design problems. The research methods used are literature reviews and conception design with empathy. This paper also tried to discuss various issues from different aspects. Nowadays, we have been influenced by technologies in our daily life. Even our cultures, life styles, and behavior, etc. are deeply changed. However, there are few ways we need to think what will happen in the future and how we could imagine possible ways to solve all of these problems. This research has proposed The Virtual Home (T.V.H.), which is a way to change the mass media dissemination and information control. The T.V.H. designed with some functions is trying to centralize all kind of mass media and help save natural resources.
\end{abstract}

Keywords: conception design, empathic design, mass media, technology, culture \& changes, imagination

\section{Introduction}

Everyday, we receive different kinds of information no matter we like it or not. And we have to live with a big amount of information through newspapers, books, magazines, TV, broadcasting, Internet, etc. Gradually, as we get used to it, we don't know the information we get is wrong or right. "How do the visual media affect our lives?” It is a very serious situation in Asia; and maybe, it is the same in other places. The information in advertising is more than we can control; if it is too much for the consumer, what should we do? It will consider what will happen to our environment in the future. It is important to consider what will happen in the future, if there is more advertising and information in our lives. Will it lead to a deterioration of life quality? If so, what should we do and how can we create an environment where advertising is regulated and not intrusive?

Therefore, how we think about reducing paper consumption? Are there other ways could replace the mass media? What's going on now? These issues about environment, technologies, cultures, and changes need to be examined and then propose a possible solution. A conclusion trying to bring people look at the new technologies may provide new cultures and life. New technologies provide farther thinking and improve human life.

Shu-huei Wang, Ph.D., Assistant Professor, Department of Digital Design, MingDao University. 


\section{Methodologies}

The research methods include discussion of paper issues, environmental problems, literature reviews, empathy, and conception design, etc. Literature reviews on the new media technologies and advertising problems were applied to design of the virtual home. Conception design is based on empathic imagination as a solution and outlet. The relationships among technologies, cultures, designers, and changes are shown in final results.

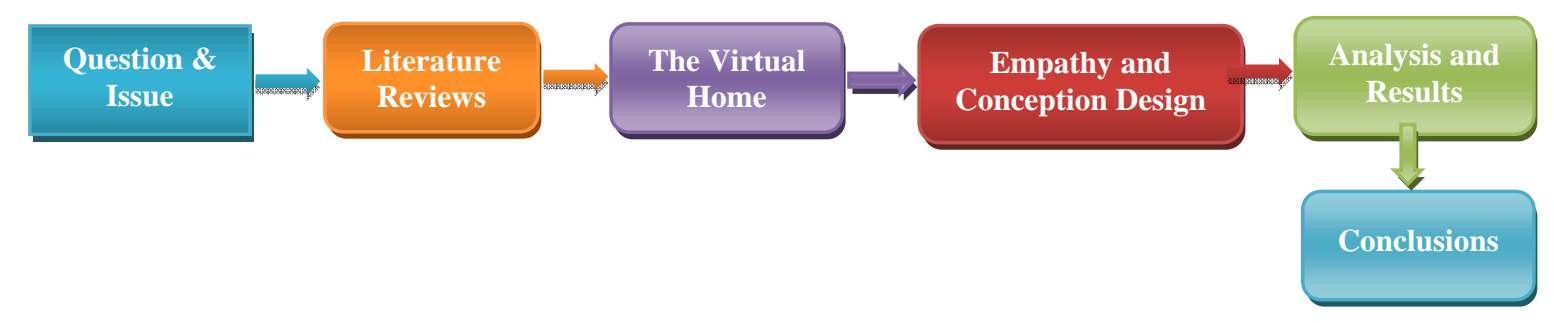

Figure 1. Research structure (illustrated by this research).

\section{Literature Review}

\section{Images and Reduce Paper Consumption}

And the design educationalist John Wood made the following accusation: "style" and "image” provide a more immediate and compelling rhetoric than durability and efficiency. But the creation of beautiful packaging for ugly or dangerous technologies should now be seen as an unacceptable task for the responsible design. There are deep questions regarding the relationship between consumerism, democracy and technology which must be addressed by everyone if we are to avoid the abyss. (Whiteley, 1993, p. 3)

This paper would like to try another way to think about the question. There is much information, which influences our lives now. The media disseminated all kinds of media images to develop the power of technology. The experiences have led me to believe that advertising could be seen as a type of pollution. This perhaps derives from that we are forced to see thousands of advertising images every day. The vast majoring of the population feeling uncomfortable with this but does not realize it. Create a view of the future, which could solve the problem of advertisement pollution.

There are many different kinds of media information, which influence our lives at present. Information is disseminating via many kinds of media images and disseminating technology, which have been developed as an information power. Therefore, people have become embraced to television, newspaper, magazine, computers, and the Internet. People have to absorb a lot of information every day. So, sometimes people do not know how to choose and to use that information. Also, it seems that mass media has controlled the behavior of population. However, there is information, which should be used, available to all. Because, the media has been invented by the people. If there is possibility to concentrate all kinds information (for example, television, newspaper, magazine, computers, and the Internet, etc.), by amalgamating their into a The Virtual Home (ex: information mixed-media). Most of the newsstand on the streets could be replaced by this T.V.H.

First of all, it is a product for individuals. If people use the T.V.H., then they would enjoy all kinds of information. It changes the way mass media is disseminate of information and makes new way of controlling information. Secondly, it can solve some problems of paper industry. For example, the newspaper industry 
consumes a great deal of paper every day. It cannot solve all problems of paper media. But, it can also solve some of the environmental problems. However, there are many questions which rise. For example, what is the "The Virtual Home and what kind of changes will happen?” The dream could become true. Furthermore is the relationship around culture, technology and designer and how would the technology help people get better life?

\section{The Visual Media Affect Our Lives}

Altschull argues that: "From the very beginning, newspapers have been used by those with commercial interests as a source of information in surveying the environment” (1984, p. 60). We can see newspapers bringing us information every day; unknowingly our consumer behavior has been influenced. There are four main media that influence on our daily lives. For example, TV, Newspapers, Magazine, Radio are influential on consumer behavior in everyday life. These media are powerful, as Altschull points out:

Advertisements were a way to confirm support for individual papers by the business community, just as the earlier proud pronouncements that certain newspapers were issued on the authority of government were a source of confirmation of the worth of the product. $(1984$, p. 62)

So, the government had to play the role of supervision of the media. Also, the media have the right of freedom to report the facts. But, what is true? At the same time, the economic role of advertising is very important to customers and the media. Therefore, we can see advertising from several perspectives, as an important communication medium for the public and consumer, however, it is also used to persuade consumers through misleading information, which could be defined as a form of "visual pollution". Paper advertising is also wasteful of resources, which also creates environmental pollution.

New technology brings us to a new age, where the medium is more active than before. Moreover, the advertising used in the medium disseminates commercial information to people more frequently. For example, Herman and McChesney comment that, "When combined with satellite communication and fiber optic-wired communication networks, digital communication becomes the 'information superhighway' or the 'Global Information Infrastructure”' (1997, p. 106). Therefore, we can see that the media as conveyed through information technology, has become more widespread and influential. Also, Personal Computer Technology and Information Technology are becoming a necessity for modern living and learning and an intrinsic part the "home" and also of family life, the school, and the office environment.

Diversified electronic communication systems have been followed by advertising and advertising now fully uses these new opportunities. Herman and McChesney observe: “At present the information superhighway largely remains to be constructed, but rudimentary digital communication networks-especially the Internet—are changing the media landscape” (1997, p. 106). Therefore, is technology and media changing and advancing so quickly that we cannot understand its new form and how to manage and interpret digital information?

\section{The New Media Technologies VS “Visual Pollution”}

New media technologies represent information in many different ways, and sometimes people do not understand how this is changing their lives and how new information mediums are influencing them psychologically and physiologically and their lifestyles and habits. New information technologies and information dissemination have often been introduced undemocratically and without warning or discipline. 
Moreover, the power of advertising and business means they can introduce new technologies and information mediums and content, without consent from people or the consumer. For example, on the Internet we can find many sexual images and they come from different places (countries). As Herman and McChesney suggest:

It is likely that the global media firms will be able to incorporate the Internet and related computer networks into their empires, while the egalitarian potential of the technology is minimized. Yet we are at the beginning of the digital era, so prediction beyond broad brushstrokes is problematic. (1997, p. 107)

However, we should think about how this technology may provide more choice for people. If there is too much choice that would become another problem and people will find media corporations are intrusive and overtly persuasive. Therefore, how can the consumer deal with increasing amounts of information and which is not relevant or obscene? Could consumers' confidence in such technologies be improved through empowerment and "The Virtual Home"? As we enter a new technological age based on the dissemination and flow of information, how will new media technologies allow people to manage and select the information that they need? We do not yet know how the Internet will develop in relation to the consumer. As Herman and McChesney state: "The nature of the communication system that the media giants do dominate is in the midst of sweeping change, introducing new players, new possibilities, stunning technological developments, and considerable instability” (1997, p. 107).

The new media corporations will soon control the market more widely, and it seems that these powerful media companies could exert considerable advertising influence over the consumer through new media technologies. We must think about how these new digital technologies can be used more effectively to give consumers control over the information they require and to reduce the need for printed advertising, which is consuming vast non-renewable natural resource.

Sinclair asserts the following: "Whilst advertising might exert an ideological influence upon society, it is distribution which determines much of its spatial and visual environment” (1987, p. 96). The global media destroys worldwide boundaries. However, different countries have different cultures. I could discuss the intercultural difference of "visual pollution". For the moment, I have just discussed the general situation common to any country. Then we can look at how the "Green issue" gives us a way to think about how could we keep our earth clean and save energy. I have been talking about "visual pollution", however, how can we control our choice of information more effectively, so as to reduce information overload and reduce the intrusive media? How can we plan human lives and an organised society (community)? Can we reduce the need for paper advertising and translate it into a digital format so as to prevent the pollution? Maybe we can use new and more democratic technologies which give more power and choice to people. Accordingly, "The Virtual Home” may solve the issues addressed in this paper and reduce resource consumption by consolidating information to a centralized point that people can feel more at "home" and thus more comfortable with the new media technology.

\section{Advertising Visual Communication and Visual Pollution and Environment}

We are in the 21st century. We have a lot of information and technology around in our lives almost every day. Therefore, we are being forced to accept a lot of information in our lives. Sometimes we are unaware of this. So, It would like to ask the question: "Is advertising visual communication and visual pollution in our environment?" 
It may appear that our lives are full of all kinds of visual images, but we don't realise how they may be unhealthy and uncomfortable to look at or affecting peoples psychology. "Part of the difficulty designers face in creating environmentally sensitive work is due to a failure of imagination as much as a failure of information" (Ortbal, Lange, \& Carroll, 1996, p. xv). we should ask, “what is visual communication?”: When advertising their products to the public, promoters use many forms of media. Promoters have a responsibility to the consumer for their images. However, if there are too many images in our environment and whether or not they are intrusive in our lives and a discomfort to people?

There are several kinds of ways in which we can perceive "Visual Pollution", but, many people and consumers do not know that it has a harmful influence on our psychology and also our physiology. Therefore, it is important to remember this, as Gillian Dyer notes:

There are several perceptual exercises such as visual illusions and puzzles and unfamiliar diagrammatic representations which demonstrate the general the way in which our brains deal with the information it receives; how we are selective about what we see and how our previous learning and experience constrains our perception. (1982, p. 96)

We can find clues to this in our daily lives. If we are not concerned about the situation then it may be harmful to both our bodies and spirit.

Therefore, it argues that we should develop a system, which can consolidate information, so that people can be in more control of what information or advertisements they wish to look at. For this to happen we need to understand how we use media and communication systems, and examine the potential invisible harm it does to the public as a form of "Visual Pollution". Moreover, in support of this argument we should analyze different examples of "Visual Pollution": If people have the same feeling about "Visual Pollution”, then they will be aware of the damaging influence it has on our health and psychology.

\section{The Visual Communication}

In Modern times, we can see advertising everywhere in our daily life. Advertising is communication to consumers of produce, services and ideas. Gillian Dyer writes that "In its simplest sense the word 'advertising' means 'drawing attention to something', or notifying or informing somebody of something” (1982, p. 2). Therefore, if we want the public to know what product we sell, we normally use large images or words. But, sometimes advertising uses too much information and visual image to create desires in human life. As Gillian Dyer observes, "Advertisements create false wants and encourage the production and consumption of things that are incompatible with the fulfilment of genuine and urgent human needs" (1982, p. 3). However, in this chapter it would like to talk about what is good visual communication and general visual communication.

It would briefly like to argue that good visual communication talks about essential development in our world. Also, we need information about this in our daily life. Dyer has noted:

Consumer goods are necessary and important and on the whole have been a welcome development of the modern world. But along with commodities we need information about them: about their price, function, durability, quality, etc. Thiskind of information help us make wise and rational consumer choices. (1982, p. 4)

As we understand it she is arguing that we do need advertising, but she is also wondering if it is beneficial to society. On the other hand, it is difficult to recognize what is a welcome improvement of society. So, there are suggesting that we look at "good" visual communication and "general" visual communication. 


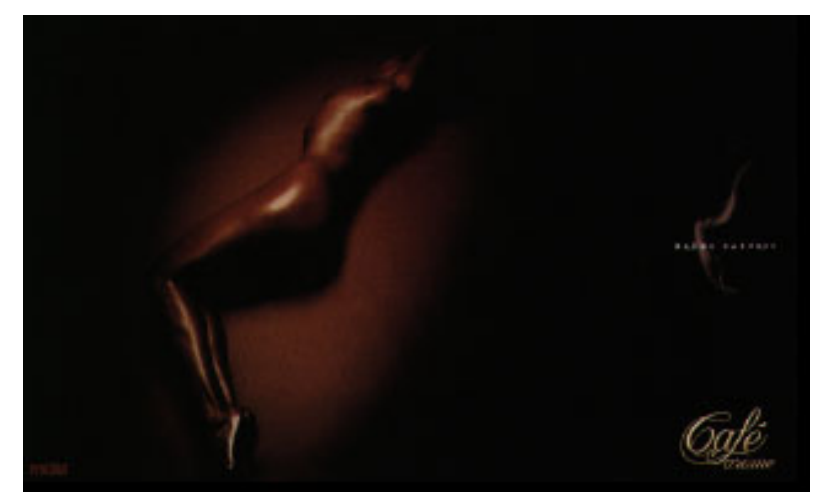

Figure 2. “Natural flavor” (magazine “ARCHIVE” 1-1999, p. 33).

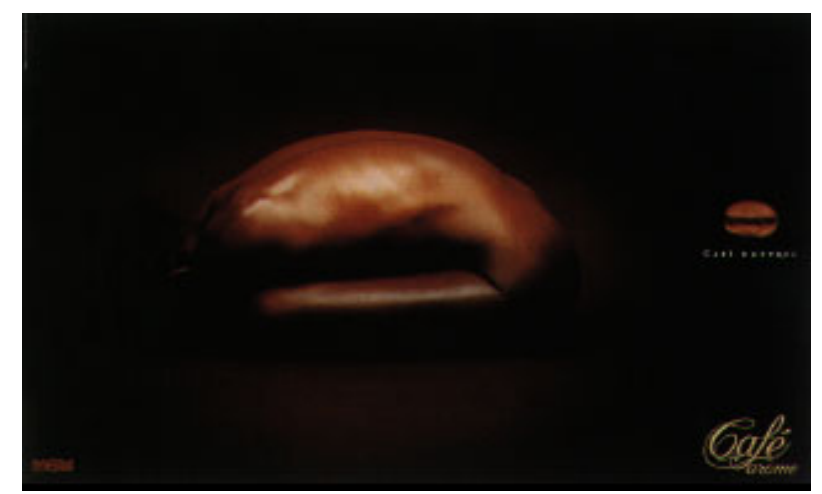

Figure 3. "Natural coffee” (magazine “ARCHIVE” 1-1999, p. 33).

For example, in Figures 2 and 3 we can see the concepts in a coffee advertisement. "Natural flavor" in Figure 2 uses the "Natural" Body to convey the coffee's aroma. Figure 3 uses physical similarity of the body to the coffee bean. These advertisements are examples of good visual communication: they show the creative idea and the clear coffee brand. It is obvious that the advertisement would influence people to buy the product. Dyer points out that "Advertisements not only influence overall media policy (although this influence is very subtle), they also affect or modify the 'look' of media production” (1982, p. 10). We can contrast this with another example. Figures 4, 5, 6, and 7 have differences between concepts and the visual. But, they have a similar ideology to a good advertisement.

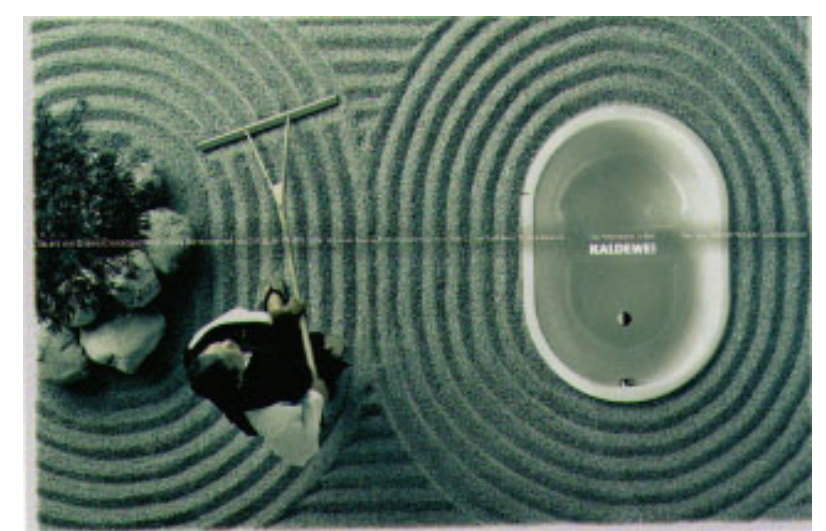

Figure 4. "Things you need to use daily don't need to have an everyday look about them” (magazine "ARCHIVE” 1-1999, p. 79). 


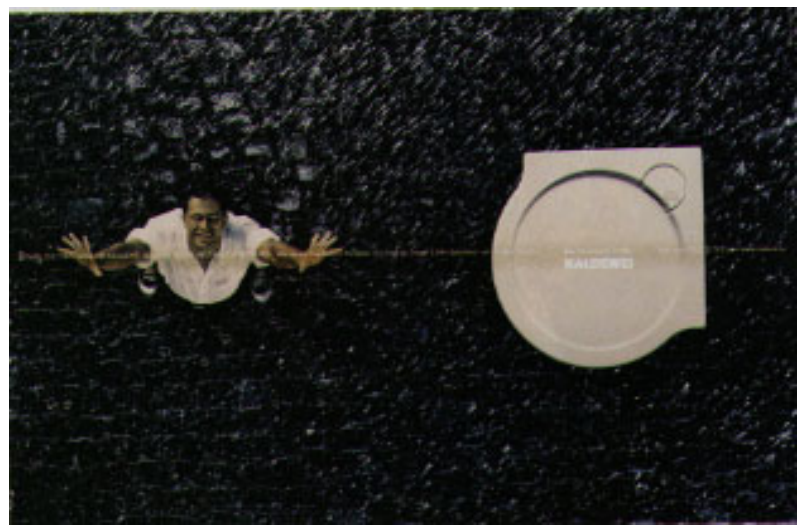

Figure 5. "Even a requisite for everyday use can be a messenger of cultural values" (magazine "ARCHIVE” 1-1999, p. 79).

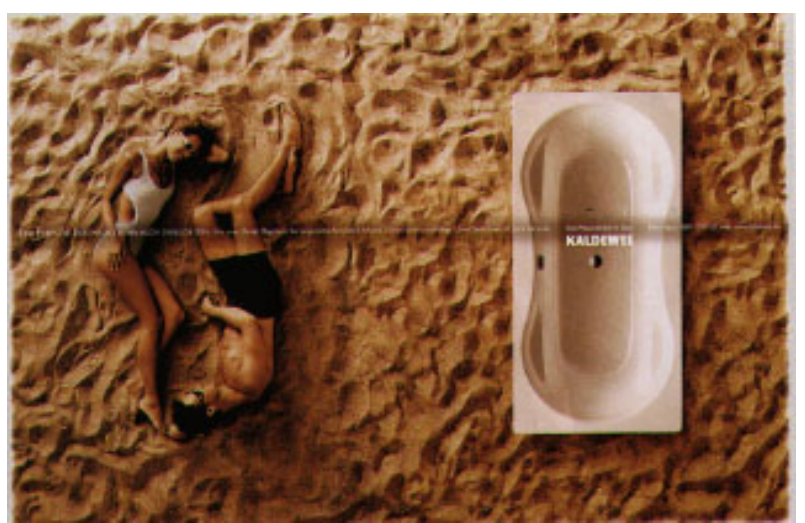

Figure 6. “A shape that makes sense can also be a sensual one” (magazine “ARCHIVE” 1-1999, p. 80).

Vestergaard and Schroder argue that "The relation between text and picture, and the ways in which we communicate by mean of image, i.e. The relation between image and the content they communicate” (1985, p. 33). They show the meaning of images and also the product very clearly. They use comparison, the difference between two objects, to convey the meaning of the image.

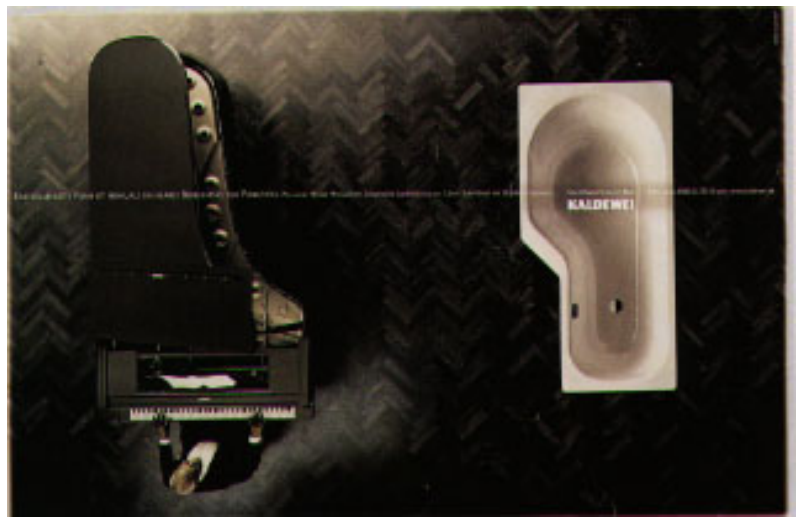

Figure 7. “A perfect shape is more than a clear profession of function” (magazine “ARCHIVE” 1-1999, p. 80).

There are some general visual communications advertisements we could consider. Vestergaard and Schroder say that, "Of Particular interest are the facts that the role of object is not filled by the product but by 
some quality or state associated with it, and that the consumer (the 'you' ) is both subject and receiver” (1985, p. 29). We can see that these advertisements often use some imaginative images that do not directly state why the consumer needs the product. They are showing us that we may need something. For example, Figures 8, 9, 10, and 11, these advertisements can be discussed and compared. As Vestergaard and Schroder point out:

No one would deny that images communicate, but the trouble is that this fact does not warrant the conclusion that images can be analysed in ways analogous to the procedures of analysis applied to the means of communication par excellence. (1985, p. 34)

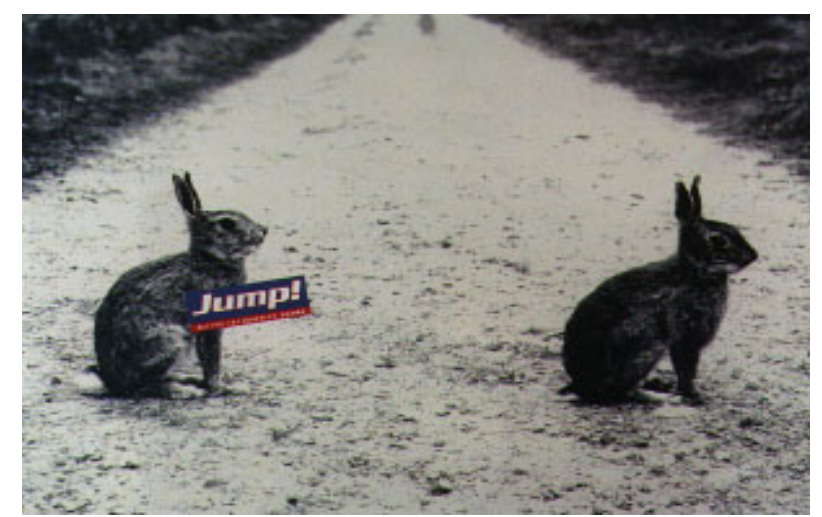

Figure 8. Part of a “Campaign for an energy drink” (magazine “ARCHIVE” 1-1999, p. 40).

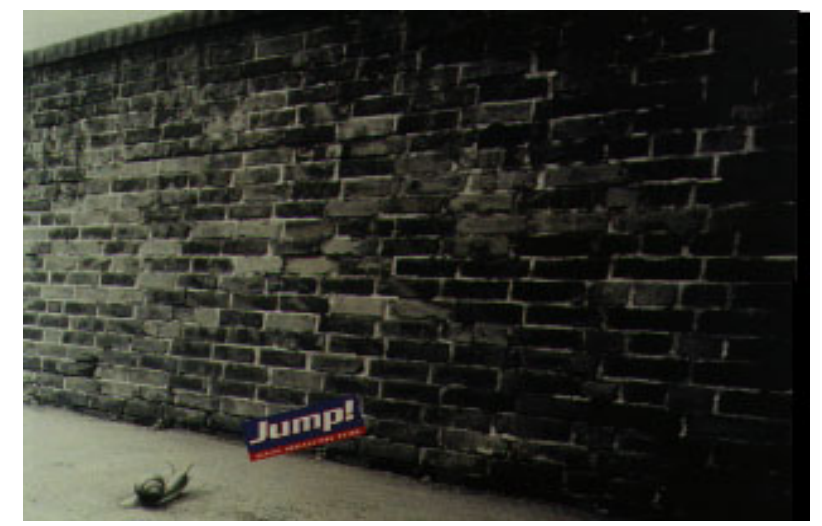

Figure 9. Part of a “Campaign for an energy drink” (magazine “ARCHIVE” 1-1999, p. 40).

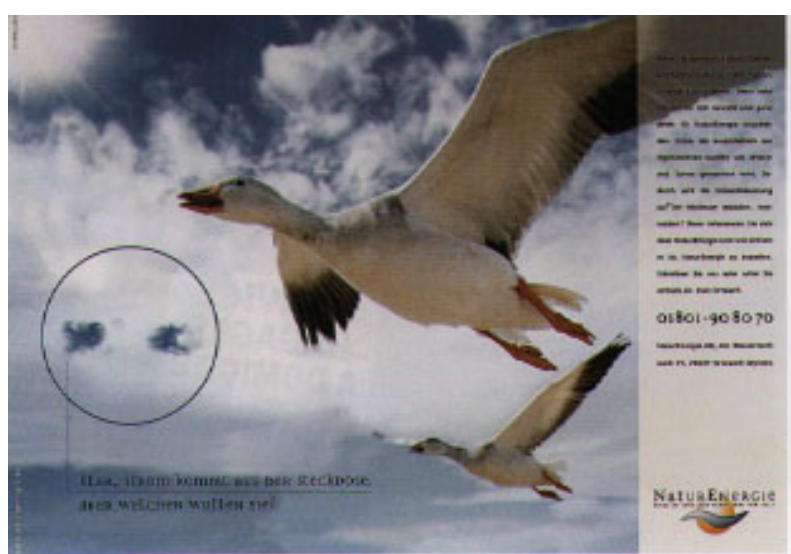

Figure 10. "Sure, electricity comes out of the wall socket. But which kind do you want?" (magazine "ARCHIVE" 1-1999, p. 114). 
The drink advertisement uses metaphorical humor to show that if people drink it they will have more energy to do anything. Then we could consider Figures 10 and 11. The combination of ingenious visual metaphor and text conveys the product to the consumer. We know that there are many kinds of advertisement surrounding us in our daily lives. However, when planning a campaign advertisers do not stop to ask if there is too much information in our environment. We should think about whether advertising uses too much media power on our lives, “Visually Polluting” our daily existence. In the next chapter will discuss "What is visual pollution?”.

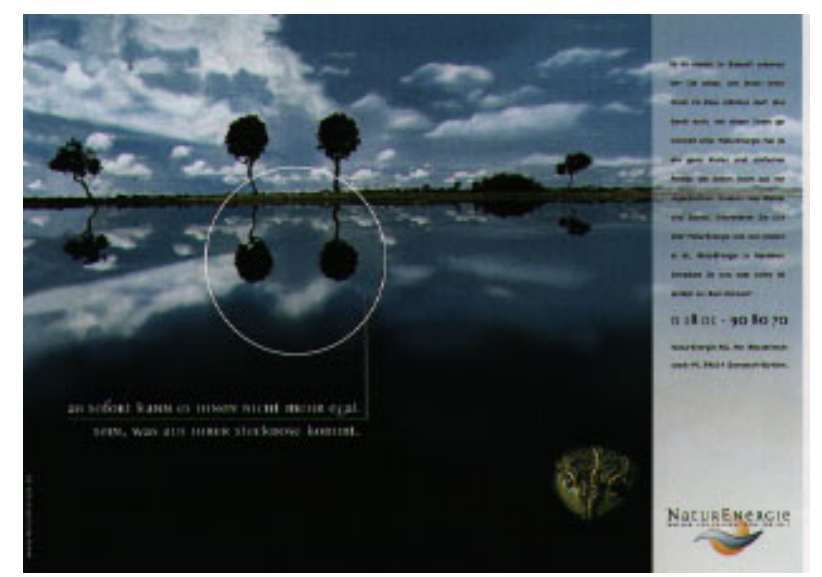

Figure 11. "From now on, you can no longer afford to ignore what comes out of your wall socket. Campaign for a company exploring alternative sources of energy” (magazine “ARCHIVE” 1-1999, p. 114).

As Ortbal, Lange, and Carroll write:

By design, we have set ourselves up in a system of daily life that ignores and insults the natural world in so many ways that we no longer are even aware of the damage-and we certainly don't seem to be able to stop it without threatening our current system of wealth. (1996, p. xiii)

So, the "Visual Pollution" is the situation in our every day lives. But, we are neglectful of the situation and we do not know how we feel. Professor Mary Douglas argues that "Pollution ideas work in the life of society at two levels, one largely instrumental, one expressive” (1996, p. 3).

How does advertising use too much promotion for products? We can see many posters stuck on walls and polluting our environment. Douglas (1996, p. 11) discusses ideas about purity and danger. She states "Primitive rules of uncleanness pay attention to the material circumstances of an act and judge it good or bad accordingly”. But, discussing modern times, there are some different new problems in our daily lives. For example, "ecology” and "Eco-design": what is their relationship with the earth and environment? The meaning of "ecology" is "study of relations of living organisms to their environment; study of ecosystems; study of the environmental conditions of existence” (Croall \& Rankin, 1992, p. 5).

Eco-design should decrease the waste of resources in our Eco-system. So, let me show some examples to explain how advertising uses too much promotion in our environment (every day we live here). Figures 12, 13, 14 were taken photographed in New Cross Road London UK. You can see advertisements on signboards everywhere. It is not organized on the street; we can see signboards at random on walls and they disorder our environment. It's another kind of what we call "Visual Pollution”. Also, advertisements use papers to paste on walls like Figures 15 and 16. We can see that disorder creates dirt in our lives. As Croall and Rankin describe: 
The world "is now lurching from one energy crisis to another, threatening at every turn to derail the global economy or disrupt its environmental support systems. The nineties are likely to be plagued by more frequent and more severe energy crises than ever before”. (1992, p. 93)

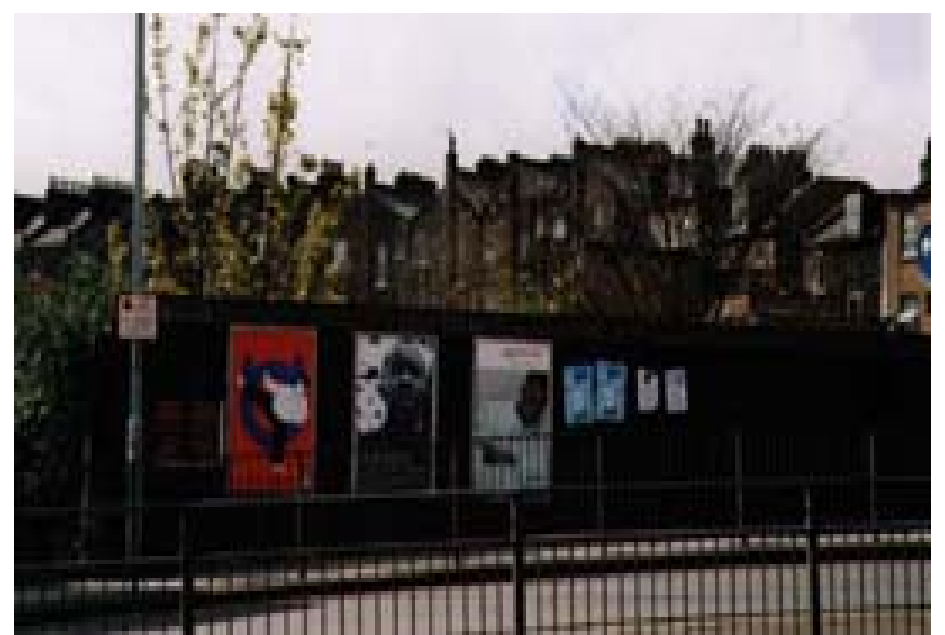

Figure 12. London New Cross Road photo by this research.

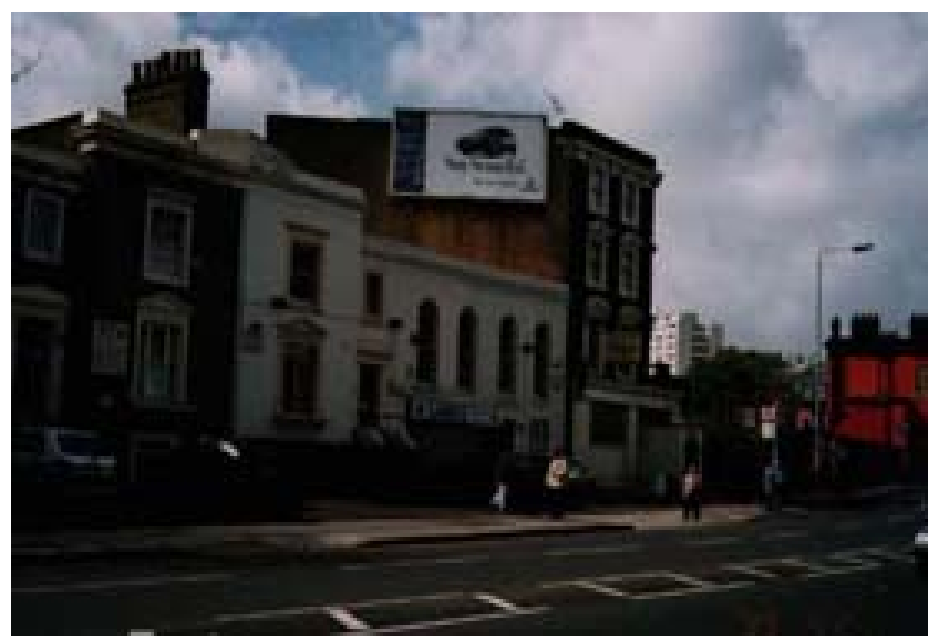

Figure 13. London New Cross Road photo by this research.

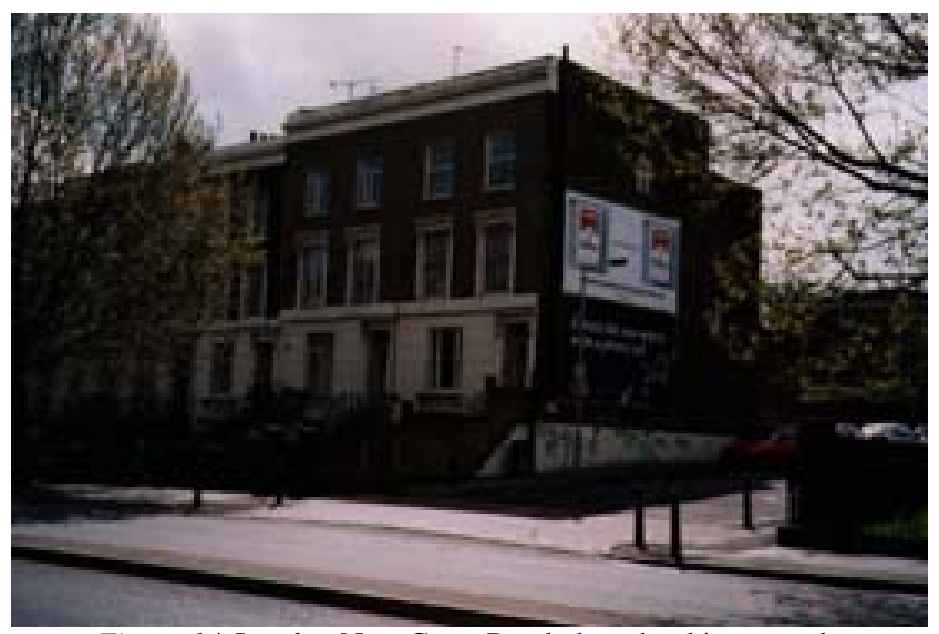

Figure 14. London New Cross Road photo by this research. 


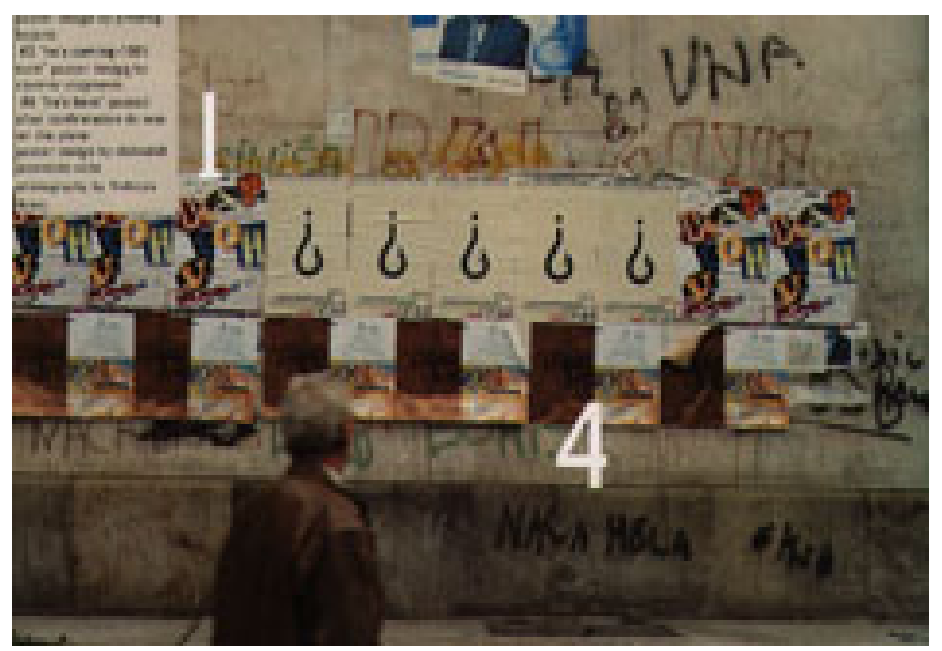

Figure 15. David Carson (1996) “Vid Carson: 2nd sight text: lewis blackwell”, New York.

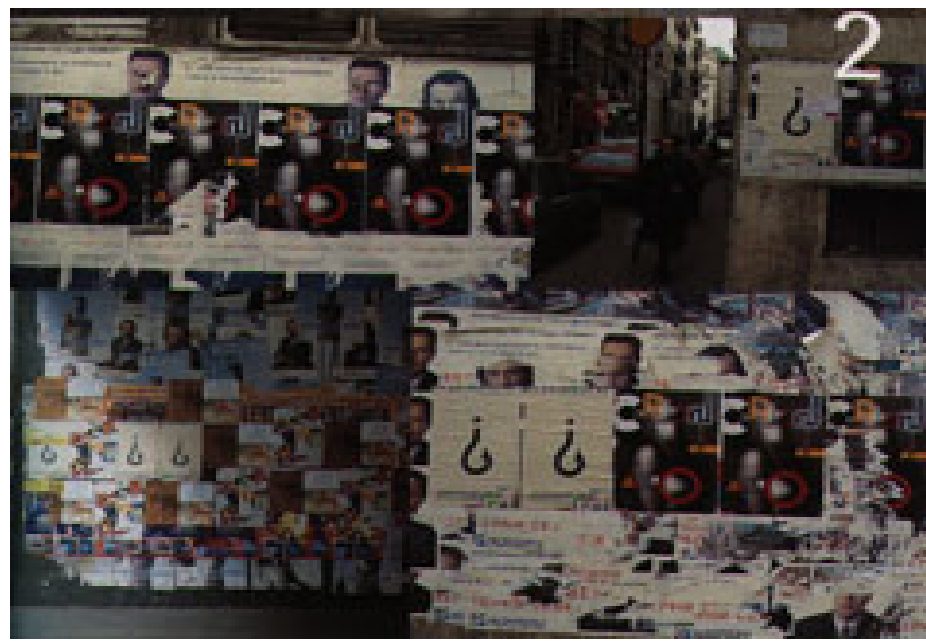

Figure 16. David Carson (1996) “Vid Carson: 2nd sight text: lewis blackwell”, New York.

\section{The Virtual Home}

Post-Modern is fundamentally the eclectic mixture of any tradition with of the immediate post: it is both the continuation of Modernism and its transcendence. Its best works are characteristically doubly-coded and ironic, making a feature of the wide choice, conflict and discontinuity of tradition, because this heterogeneity most clearly captures our pluralism. (Jencks, 1989, p. 7)

\section{The Meaning of the Virtual Home}

The Virtual Home embraces a view of the future, which we could mix different media to converge. People use disk or compact disk choose newspaper, magazine, television programs, radio, film, internet, computer, game etc. and choose which kinds of language down record bring back (take away). The news of the world, which you are looking for and the diversity of language would not be a problem. "Mixed" meaning comes from post-modern the character which is, different rationality for different areas of problem solving, different kind of rationality for different cultures. That is why name "The Virtual Home" (see Figure 17). 


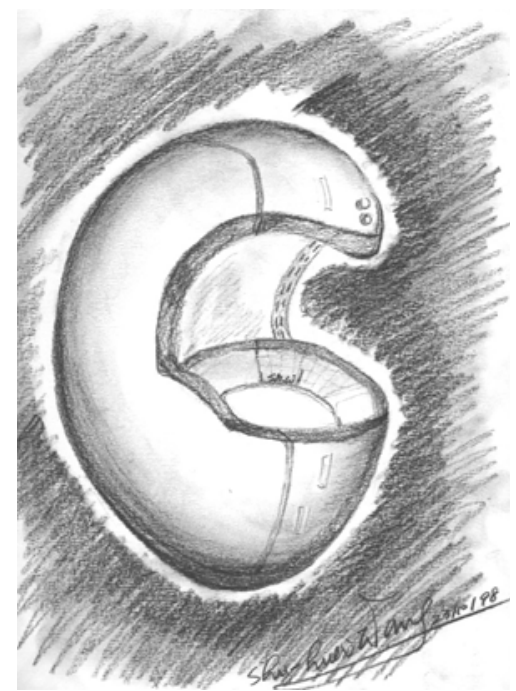

Figure 17. One possible image of The Virtual Home (illustrated by this research).

\section{The Virtual Home’s Functions}

Magnetic disk storage sufficient to hold 1,000 books the size of this one cost about \$2,000 in 1994. CD-ROM storage is even cheaper. Such devices occupy about one-fourth of a cubic foot of physical space ...Floppy disk and CD-ROMs can be sent by ordinary mail, then mounted either on individual PCs or on server machines attached to a network ...So with all these advantages, why is electronic delivery not here. (Landauer, 1995, p. 248)

The Virtual Home will substitute for newsstands in the future (see Figures 18 and 19). Comparing Figure 17 with Figures 18 and 19, what is difference between them? In Figure 17 there is no paper needed. It only focuses on people, we are not necessary reading too much imageries in advertising and pollution our lives. Secondly, we do not need large amounts of paper. It could save natural resources. People use disk or CD buying and recording down then bringing home. And then according to the characteristic of this material, they can use this information again and again. That will save some paper and perhaps change the traditional way of disseminating mass media. Next, we can use solar power and solar cells to solve the electric problem. When some people say technology is damaging our life. However, it could contrast, be used as the tools for making human life better? For example, Nick Heap, Ray Thomas, Geoff Einon, Robin Mason, and Hughie Mackay note: "Worker participation in new technology introduction tends to be beneficial in terms of efficiency as well as humanity” (1995, p. 147).

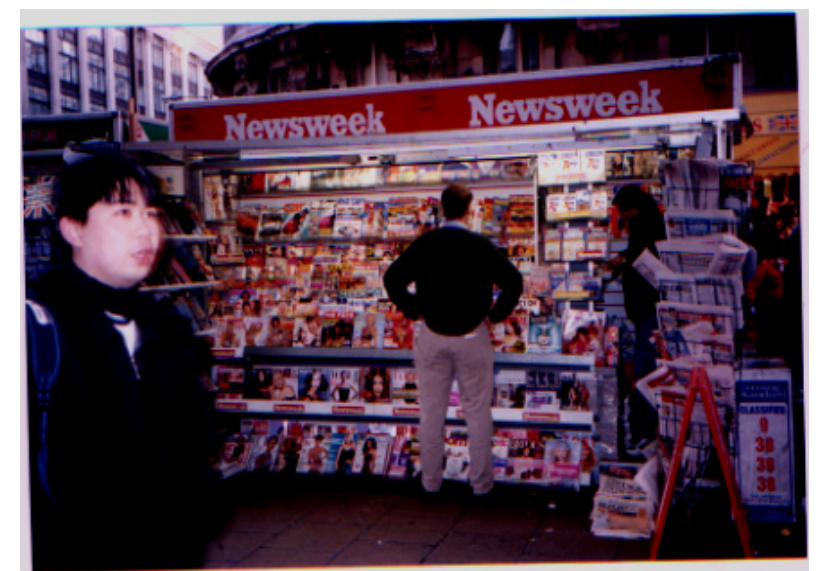

Figure 18. Newsstand on near China town street at London (photo by this research). 


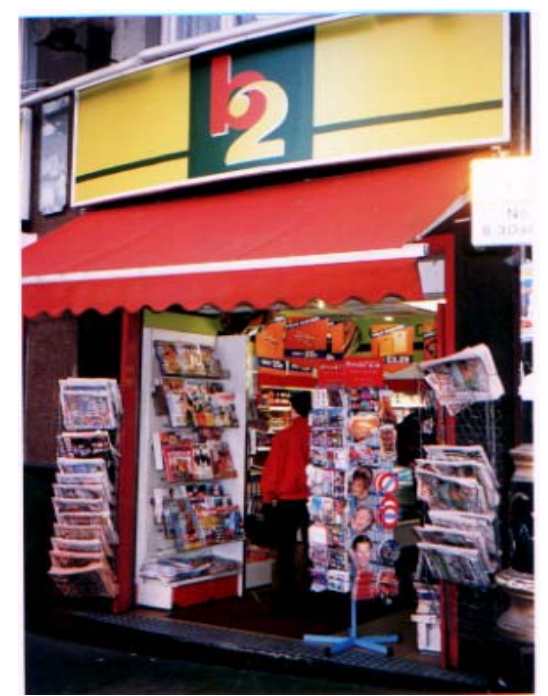

Figure 19. Newsstand on near China town street at London (photo by this research).

The Virtual Home has several functions. If one person, stands inside, he/she could choose all kinds of media on the keyboard, using pay card for money and choosing the language they need. Although, The Virtual Home can be put in any public place or put together in stores servicing more people. It depends on how we would do and what situation we need. At the same time, the most important is that people are interested using in this machine or not. From this point of view, we use technology for helping to solve problem that manpower can not supply. Thomas K. Landauer said:

Cost reduction is only one part of productivity improvement. Arguably, a more important part will be the development of new information products—new useful information, new usable packaging and delivery of information. Current online database systems are just a beginning. (1995, p. 356)

\section{Empathy and Conception Design}

"When one changes from one milieu to another, it is not just the meaning of an object which changes, but also the structure of all its features, both formal and material” (Diani, 1992, p. 46). Empathy, a bridge for communication, establishes a common consensus even in different cultures. Just as Rifykin (2001) indicated that mankind is capable of understanding others and searching for a common view through empathy. Empathy is a feeling that helps social trust grow. The so-called empathic sympathy depends on whether you can put others into your own imaginative space or not. It is one of the deepest emotions of human beings as well as the creator of cohering a close relationship and modesty among people (Rifykin, 2001). Empathic design uses cultures and imagination as the motive force for creation.

When we look at "the beginning of the 19th century, the paper industry began manufacturing its product mechanically rather than by hand” (Wood, 1998, p. 2). And now people have been getting used to paper, most of them do not want to change. But please, let us see in "1848 A.D. The rotary press achieved 24,000 pages printed in an hour" (Wood, 1998, p. 2). That meaning of the nature is how many trees had been cut. And late "20th century - more than a million pages an hour can now be printed". "Today about 32,000 separate new titles are published each year in the U.S.A alone”. And "1983 A.D. The Reliance Insurance Company in Philadelphia planned to make its office 'paper-free in 1983' using computer and telecommunication” (Wood, 1998, p. 2). So, 
look at our world now greenhouse effect and ozone layer problem. Because of too much pollution, that is why earth is sick and ecology balance had been destroyed.

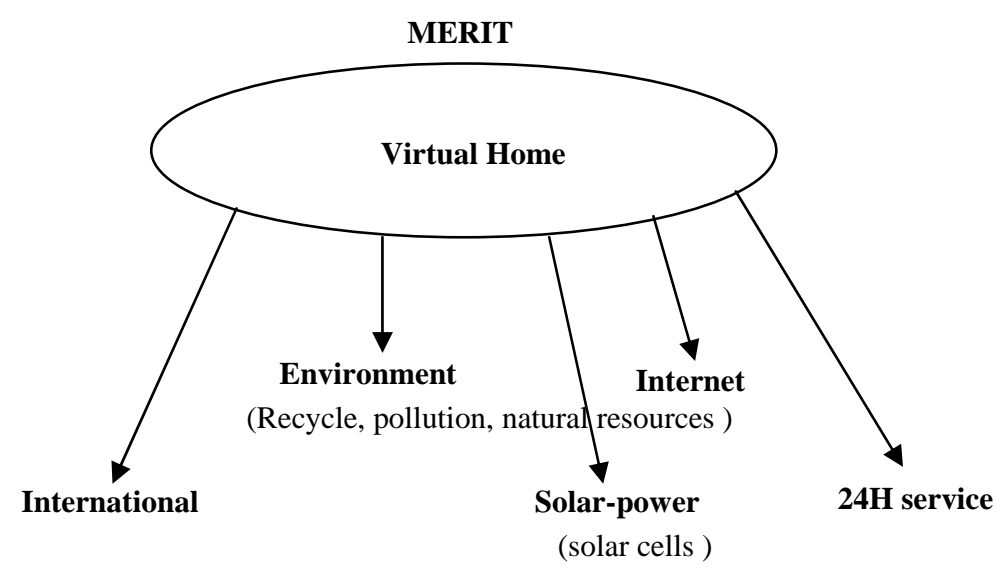

Figure 20. Merit of Virtual Home (illustrated by this research).

Merits of Virtual Home contain 5 main features of international, the Internet, solar, environment and 24-hour services like using solar energy to provide clean and sustainable electricity. We need a lot of bold imagination to create our future. It is possibly becomeing truth.

The Virtual Home could not solve all environment problems, but it will improve some environment problems. However, its need people like to use and then help changing of human life.

We need to re-invent what we do. We can take responsibility for the environmental and social effects of our work. We can grasp new information educate ourselves, develop new creative ways. The nineties are the biggest opportunity for imagination and boldness our species, and our profession, have ever had. With the highest make-or-break stakes. (Whiteley, 1993, p. 3)

We can read from the chart showing The Virtual Home may provide our life in many ways. It maybe change human life style and the mass media in the future . We do not say how wonderful it is for human. In face, it still has few problems which we need to investigate. For example, people can not read and memorize from the screen, from my questionnaire we could know, some people have been already used read and touch with paper. Therefore, designers have to concentrate that the function of T.V.H. like the degree of people using.

Where everyone does most of their work near a desk, it will be easier. Portable computers with wireless communication will help but not suffice. To support complex information work, people need good, big screens and full-sized keyboards. Otherwise paper is more efficient and pleasant, and people rightfully hang on to it. That is the hardware end of the deal, except for high-capacity highly reliable networks. (Landauer, 1995, p. 355)

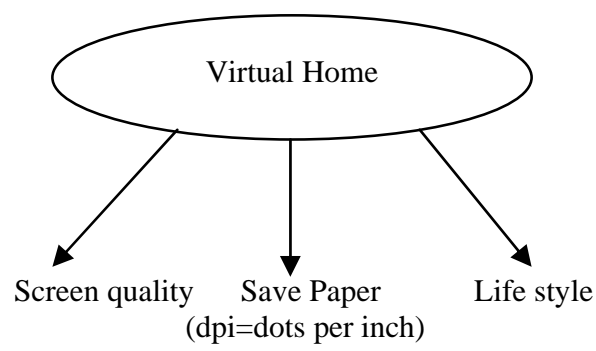

Figure 21. The possible of The Virtual Home (illustrated by this research). 
We can discuss about those few main problems. Firstly, people could not read and memory from screen more than paper. "1991 A.D. Experiment by researchers shows how a sample user group when given timed reading tests, Learned from and preferred, a paper version of a hypertext document” note by McKninght etc. (Wood, 1998, p. 3). Secondly, "the advent of the internet has increased the amount of paper used...we read on the screen and then reach for the PRINT button!!” (Wood, 1998, p. 3). In addition, “reading on the screen is inefficient for writing and editing” (Wood, 1998, p. 3).

"Larger screen televisions today generally use one of several projection technologies, all of which suffer to some extent from limited brightness or viewing angles in comparison with picture tubes” (Wood, 1998, p. 3). That is why people could no longer watch screen and because the quality still need improvement. Then, people may be more easy to watch. "To make HDTV sufficiently impressive on consumers, it should be displayed on a screen with a diagonal measurement of, at the very least, 1,000 millimeters (or, better yet, 1,250, 1,500 or more)" (Wood, 1998, p. 3). We know about the diagonal measurement quality the more, then we could get more steady. For example, "engineers at NEC recently demonstrated a 1,270 — millimeter (50-inch) screen in the 16:9 width-to height ratio of HDTV” (Wood, 1998, p. 3).

...a large literature shows that the resulting decisions are usually no batter. The use of paper in offices has gone up twice as fast as GNP. Many observers have commented on the increased aesthetic appeal of carefully formatted casual memos and charts and the explosion of unnecessarily detailed business cases. (Landauer, 1995, p. 332)

Some people are addicted to paper, who I asked people fill in the questionnaire. So, if we invent some kind of a more legible screen and make it like paper, it could change the addiction to paper. When people like to use it and do not have any uncomfortable, then it could show that we ameliorate paper media problem, and hopefully can save from gradually critical environment problem. So, it is very important that we can use card or disk to recycle and do not waste natural resources.

"Consumer-led design in a market economy goes far beyond the idea of meeting human need: it seeks to create and constantly to stimulate human desires” (Whiteley, 1993, p. 3). If The Virtual Home cannot bring people better life and useful human, or just for stimulate human desires and human need. Also, if any change to people life style it is because people like and follow natural. So, what kind of change will happen?

\section{Analysis and Results}

"within a cultural world view that is seemingly commanded by the values of technological systems, rather than by participation and engagement within everyday life” (Hayward, 1990, p. 4).

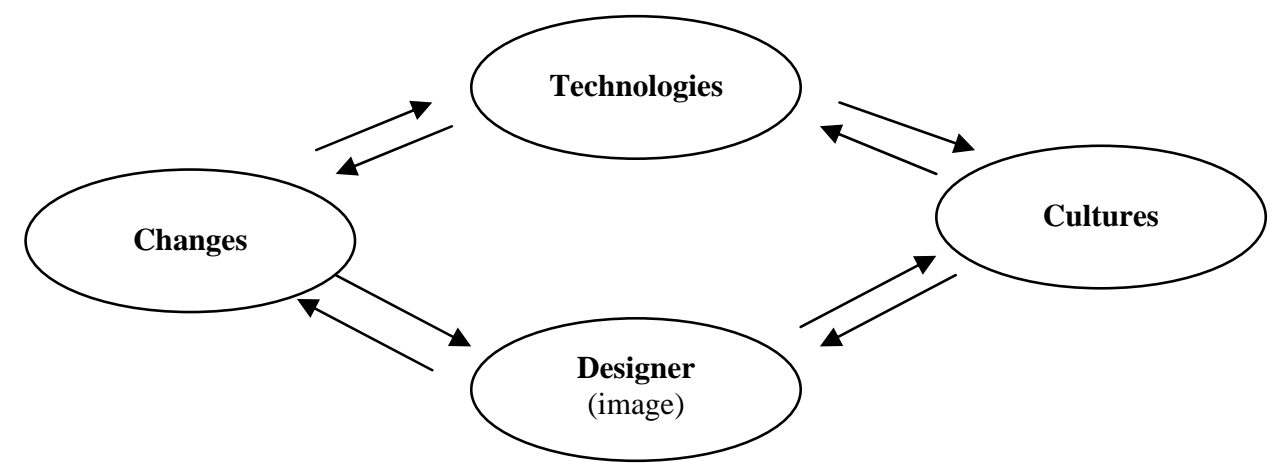

Figure 22. The relationship of technology, culture, changes, and design (illustrated by this research). 
When we look back at human history, it may tell us something about the relationship between technology, culture, designer and changes. Designers mediate between technology and culture. Just let us review that before. Culture shifts the technology and imagery. On the other hand, technology has influence on converting the culture and imagery. Similarly, Hayward mentioned that "The culture defining power of technology through an analysis of technology as a 'cultural text'-that is, imbued with cultural meanings that communicate much more than just the use value of the artefacts the mselves" (Hayward, 1990, p. 4).

After Second World War, we may look at the power of new technology, which has grown up in western society. Later, computer and information technology also have been developed our life in daily. Hayward said

The computer has only been used to copy aesthetic effects easily obtained with the use of conventional media, although the computer does its work with phenomenal speed and eliminates considerable drudgery. The use of computers in the arts has yet to produce anything approaching entirely new aesthetic experiences. (Hayward, 1990, p. 4)

Did technology bring us better life? Plainly, we could see the history process telling us. For example,

...in 1947 "train of tomorrow", in 1954 the ericofon telephone, in 1959 stereo, in 1960 washing machine, at the same time television became the center of many families leisure time. In 1957, the test kitchen of the electrical association for women in the U.K. The modern appliances removed drudgery from household tasks. (Clarke et al., 1990)

My solution may have been highly innovative, but the original problem statement was wrong. The real problem was to get rid of the mice and rats. As a fantasized solution, it might have been better to broadcast an ultrasonic or subsonic beam over every radio and TV set for a few hours. (Papanek, 1972, p. 133)

\section{Conclusion}

The ability of humans to fly today is not just the result of an invention a century ago but stems from a dream as old as hills .The dream developed into a myth and carried through history until relatively recently it became reality. (Diani, 1992, p. 38)

The using of The Virtual Home would have some influence on changing the mass media dissemination of information and making new way of controlling information. In the meanwhile, it could solve some problems of paper media. Therefore, The T.V.H. has designed with much function trying to centralize all kinds of mass media and help saving natural resources. Also, we must realize that there are some problems we need to care while using T.V.H. For example, will this change human life style, or is it helpful to the public and will people enjoy using like it or not? The meaning of T.V.H. is which could use in any country and culture. It depends on what kind culture and what kind of needs that people they want. This research had been showed follow next:

(1) Paper issues and problems discussion;

(2) The Virtual Home had future thinking for design to solution;

(3) Empathy as imagination for real experience to conception design;

(4) Results show the relationship of technologies, cultures, designers, and changes.

In Modern society, the people have become used to the convenience which technology has brought us. And it is true that we could not go back to the lives in old times. So, how do we augment the humanism in the current metals technology times, which could bring people the warm? It may be like a warm feeling, or sound more humanity, or could like a friend talking to you or in the metals technology has poetry, etc. It is really nice for people to have dream and God gives human the hope. Long time ago, flying for human was a dream. Now the dream becomes true. 


\section{References}

Advertising images. Magazine 'ARCHIVE' 1-1999.

Altschull, J. H. (1984). Agents of power: The role of the news media in human affairs. New York \& London: Longman.

Clarke, S. et al. (Eds.). (1990). FIFTIES-source book Avisual guide to the style of a decade (pp. 31, 33,35,124-125.). Great Britain: Chartwell Books.

Croall, S., \& Rankin, W. (1992). Ecology for beginners. New York: ICON Books.

Diani, M. (1992). The immaterial society design, culture, and technology in the postmodern world. Englewood Cliffs: Prentice Hall. Douglas, M. (1996). Purity and danger. London and New York: Poutledge.

Dyer, G. (1982). Advertising as communication. London: Monograph.

Hayward, P. (1990). Culture technology \& creativity in the late twentieth century. London: John Libbey \& Company Ltd.

Heap, N., Thomas, R., Einon, G., Mason, R., \& Mackay, H. (1995). Information technology and society. London: The Open University.

Herman, E. S., \& McChesney, R. W. (1997). The global media. London and Washington: Cassell.

Jencks, C. (1989). What is post-modernism? New York: Pub. St. Martins Press.

Landauer, T. K. (1995). The trouble with computers. (Vol. 21). Cambridge, MA: MIT Press.

Ortbal, J., Lange, M., \& Carroll, M. S. (1996). The ecology of design. New York: America Institute of Graphic Arts.

Papanek, V. (1972). Design for the real world. Great Britain: Thames and Hudson Ltd.

Rifykin, J. (2001). The age of access: The new culture of hypercapitalism, where all of life is a paid-for experience. (Y. H. Huang

\& Y. Liou, Trans.). Taipei: Yuan-Liou Publishing Co., Ltd.

Sinclair, J. (1987). Images incorporated: Advertising as industry and ideology. New York: Croom Helm.

Vestergaard, T., \& Schroder, K. (1985). The language of advertising. Oxford and New York: Basil Blackwell.

Whiteley, N. (1993). Design for society. London: Reaktion Books Ltd.

Wood, J. (1998). The wishing paper- Saving Trees (p. 3). 29/10/98; and Lecture notes—Saving Trees (p. 2). [Seminar Notes] 